\title{
Finite Element Modelling and Analysis of "All-Steel" Dismountable Buckling Restrained Braces
}

\author{
M. D'Aniello ${ }^{1, *}$, G. Della Corte ${ }^{2}$ and R. Landolfo ${ }^{1}$
}

\begin{abstract}
${ }^{1}$ Department of Structures for Engineering and Architecture, University of Naples "Federico II", via Forno Vecchio 36, 80134 Naples, Italy; ${ }^{2}$ Department of Structures for Engineering and Architecture, University of Naples "Federico II", Via Claudio 21, 80125 Naples, Italy
\end{abstract}

\begin{abstract}
This paper describes a theoretical investigation on the response of "all-steel" dismountable buckling restrained braces (BRBs) through the analysis of finite element models (FEMs). The focus of this investigation is on a special type of BRB developed for seismic upgrading of existing reinforced concrete buildings and experimentally tested previously. After a short summary of experimental results, the paper describes the finite element models and the analysis results. Subsequently, a discussion addresses the following issues: (i) influence of the core-to-casing clearance; (ii) influence of spacing of connections along the casing longitudinal axis; (iii) compression-to-tension strength ratio; (iv) core buckling wavelengths and core-to-casing interaction forces. Finally, the paper presents a comparison of numerical results and available analytical models.
\end{abstract}

Keywords: All-steel device, buckling restrained braces, contact forces, cyclic behaviour, finite element analysis, seismic upgrading.

\section{INTRODUCTION}

Many existing reinforced concrete (RC) structures designed prior to the development of modern seismic codes are highly vulnerable to seismic events. Hence, seismic upgrading of existing constructions is an issue of great interest, as repeatedly demonstrated by past earthquakes. In the last thirty years, this topic has been deeply investigated, with attention given to the use of energy dissipation systems based on hysteresis of steel elements [1-11]. Indeed, steel hysteretic devices have advantages, such as: (i) the potential minimum interference of the installation process with the existing building operations; (ii) the inexpensiveness of the intervention because no special technology is necessary for their fabrication and installation; (iii) design concepts and method are quite simple and the provided performance is reliable and effective.

Among the metallic devices studied in the literature, Buckling Restrained Braces (BRBs) are becoming studied and used extensively [12-18]. Thanks to their excellent hysteretic behaviour, BRBs represent one of the most efficient structural system for resisting earthquakes. BRBs brilliantly solve problems of concentric braces, which are characterized by a pinched hysteresis loop and small ductility due to buckling [19-28]. BRBs are designed to avoid the overall compression buckling, thus providing a complete truss action with the same response both in tension and compression. Hence, BRBs represent a more versatile and

*Address correspondence to this author at the Department of Structures for Engineering and Architecture, University of Naples "Federico II", via Forno Vecchio 36, 80134 Naples, Italy;

Tel: +39 81 2538917; E-mail: mdaniel@unina.it effective bracing system than concentric braces, allowing to reliably upgrade the seismic capacity of both new and existing building structures. Fig. (1) shows a sketch of a typical $\mathrm{BRB}$, illustrating also its sub-components. BRBs basically comprises two parts: (i) a slender steel member, known as the "core", and (ii) a restraining member, known as the "casing". The former component resists the axial force and has the key role of dissipating energy, while the latter component restrains the brace from overall buckling in compression. The buckling restraining mechanism can be obtained by enclosing the core (rectangular or cruciform plates, circular rods, etc.) either in a continuous concrete/mortar filled tube [12-16, 29] or within a "all-steel" casing [2, 30-36]. In the first case, the brace is called "unbonded" BRB, because the surface between the core and the casing is treated with unbonding materials to allow the relative displacement with the casing to be developed. In the second case, a void space (known as transverse "clearance") separates the core from the casing. In both types, it is necessary to leave a longitudinal clearance between the non-yielding portion of the core (known as the core "projection") and the casing in order to allow the relative core-to-casing displacement during compression phases and to avoid the transmission of axial force from the core to the casing. This longitudinal clearance is frequently called the "air gap", and such term is also used within this paper.

Possible advantages of "all-steel" BRBs over "unbonded" braces are the following [2, 31-36]:

- They can be designed to be easily dismounted by using bolted connections along the casing axis; this would permit replacement of the core without changing the casing after a damaging earthquake as well as easy maintenance; 


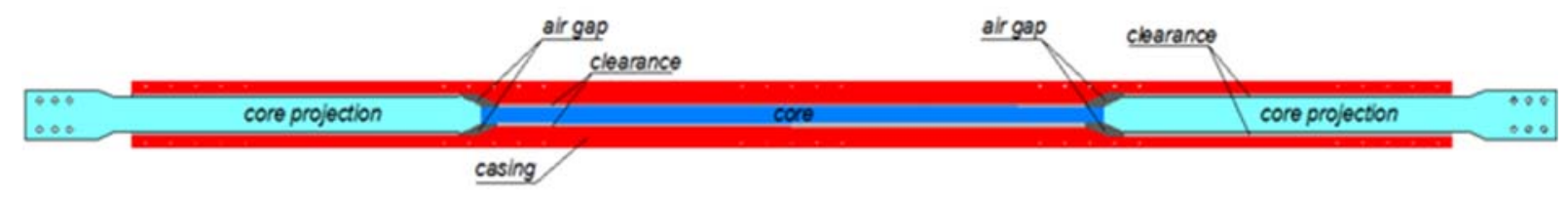

Fig. (1). Components of BRBs.

- They are made of conventional materials and with usual fabrication processes;

- They are generally lighter than "unbonded" braces.

These considerations motivated the study presented in this paper, which is addressed to investigate the behaviour of a novel "all-steel" dismountable BRB prototype. The examined BRB was conceived specifically as a hysteretic damper for existing RC frame buildings. Indeed, the main feature is the possibility to hide the device inside a void space between the two masonry panels, which are typically used in $\mathrm{RC}$ buildings as cladding elements. The efficiency of this BRB prototype was verified by means of an experimental test carried out on a real two story RC building equipped with the novel devices [37]. The main outcomes of this test are briefly described hereinafter, with the purpose to introduce the main topic subsequently addressed, i.e.: numerical models of the BRB prototype. Finite element analyses (FEAs) were carried out to investigate the following issues: (i) influence of the core-to-casing clearance; (ii) influence of the spacing of connections along the casing longitudinal axis; (iii) compression-to-tension strength ratio; (iv) core buckling wavelengths and core-to-casing interaction forces. Numerical results are finally compared with some analytical predictive models.

\section{EXPERIMENTAL TESTS}

\subsection{Geometry of BRBs}

Fig. (2) shows the geometrical details of the examined BRB prototype, which is denoted as "BRB-C" in [37]. The length of the core projection outside of the casing, as well as the length of the air gap zone, was calculated assuming a displacement capacity of the prototype corresponding to an interstorey drift ratio equal to $3 \%$. Longitudinally welded plate stiffeners provided additional transverse flexural stiffness to avoid local buckling of the core unrestrained portion. The required stiffness was evaluated by means of the stability criteria suggested in $[13,14]$. The strength was fixed on the basis of a displacement-based seismic design method [38]. The casing was made of two omega-shaped built-up members joined together by means of bolted connections. Two longitudinal bars welded on each Omega-shaped part of the casing increased the flexural stiffness and strength of the casing. On the basis of results from previous tests [2, 34-35, 37 , the casing was designed with a ratio $N_{\mathrm{E}} / N_{\text {p,core }} \approx 2$ (where $N_{\mathrm{E}}$ is the Euler buckling load of the casing and $N_{\mathrm{p}}$,core is the axial plastic strength of the core). A $2 \mathrm{~mm}$ wide coreto-casing clearance $(s)$ at each side of the core was selected. These assumptions allowed to minimize the transverse size of the casing in order to guarantee the possibility to hide the devices inside the two facades of masonry panels commonly used for claddings of RC frames [37]. Core to casing contact forces, used to both check the casing and to design the dis- crete bolted connections along the casing axis, were calculated according to available theoretical models [31]. A stopper was introduced at mid length of the casing (Fig. 2b) in order to both avoid the slipping-off movements of the casing under its own weight and force symmetric yielding of the core. Previous experimental observations [39] have shown that BRBs with stoppers exhibit a better performance in terms of low-cycle fatigue capacity. Reference [37] provides further details on the design criteria.
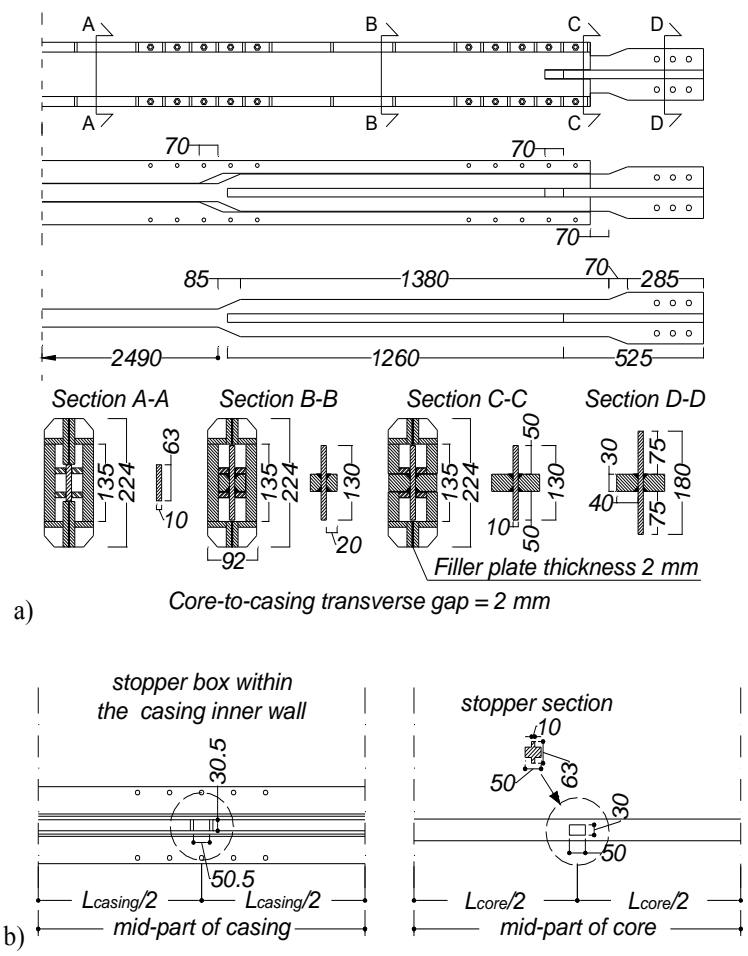

Fig. (2). Geometrical details of BRB prototype.

\subsection{Summary of Experimental Results}

Fig. (3a) shows the response in terms of normalized first storey drift ratio $\left(\theta / \theta_{\mathrm{y}}\right) v s$. normalized BRB axial deformation $\left(\delta / \delta_{\mathrm{y}}\right)$. The ratio $\theta / \theta_{\mathrm{y}}$ represents the overall ductility of the building equipped with the BRBs, being $\theta$ the first storey drift ratio and $\theta_{\mathrm{y}}$ is the first storey drift ratio corresponding to $\mathrm{BRB}$ yielding, which is equal to $0.15 \%$. The ratio $\delta / \delta_{\mathrm{y}}$ is the measure of the BRB ductility, where $\delta$ is the BRB axial deformation and $\delta_{\mathrm{y}}$ the axial elongation corresponding to $\mathrm{BRB}$ yielding. This plot highlights the strong relationship between global and local ductility. Some non-negligible difference between $\theta / \theta_{\mathrm{y}}$ and $\delta / \delta_{\mathrm{y}}$ was discovered at the unloading stages of the test, for reasons explained in [37]. Such differences are neglected in this paper and it is assumed that $\theta / \theta_{\mathrm{y}}=\delta / \delta_{\mathrm{y}}$, an approximation that appears reasonable based on Fig. (3a). 

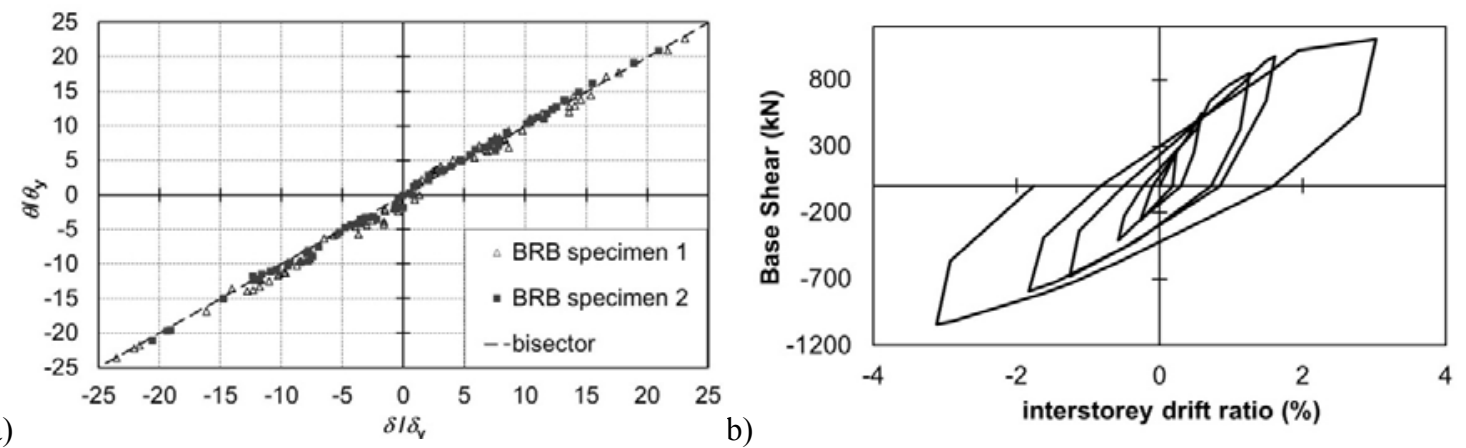

Fig. (3). Normalized interstorey drift ratios vs. normalized BRB axial deformation (a); Experimental cyclic curve (b).

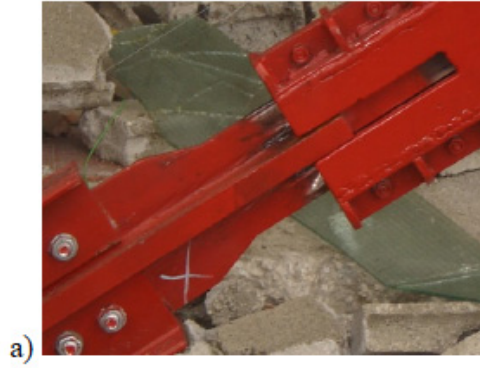

$\theta=-2 \%$

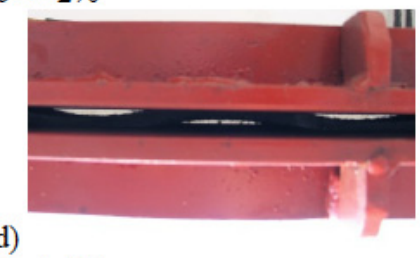

$\theta=+2 \%$
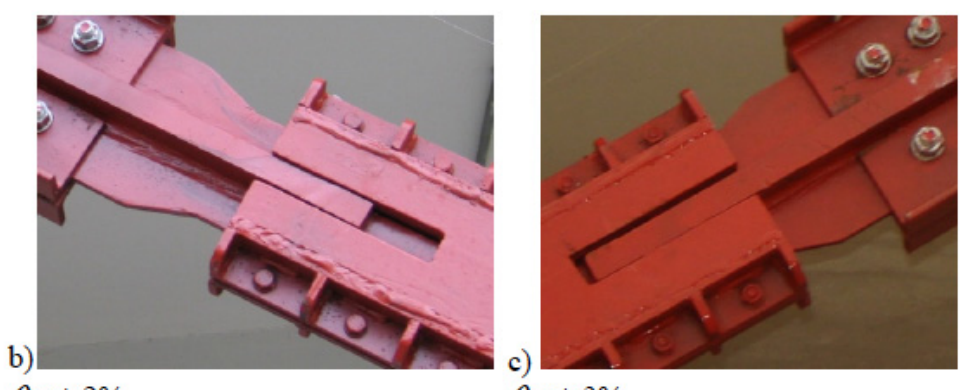

$\theta=+2 \%$

$\theta=+3 \%$

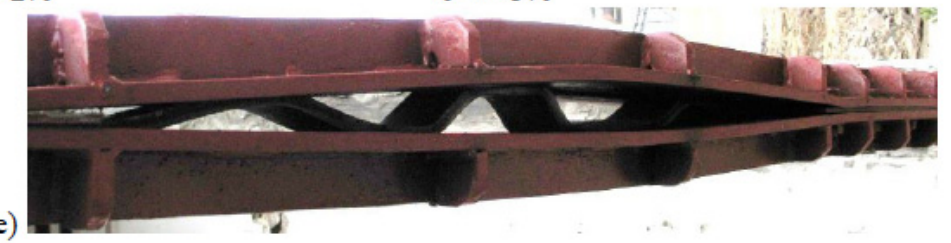

$\theta=+3 \%$

Fig. (4). Experimental damage pattern.

BRBs showed a symmetric and stable response for $\theta$ in the range $\pm 3 \%$ (Fig. 3b). The maximum ductility $\left(\mu=\delta / \delta_{\mathrm{y}}\right)$ was equal to 20.8 and the average cumulative plastic ductility

$$
\left(\mathrm{CPD}=\sum_{i} \frac{\left|\theta_{\text {max }, i}-\theta_{\text {min }, i}\right|}{\theta_{y}}\right)
$$

was equal to 349.7 , where $i$ is the index of the generic loading excursion, while $\theta_{\max , i}$ and $\theta_{\min , i}$ are the maximum and the minimum storey drift ratios at $i$-th loading cycle. These results showed that the tested BRBs can provide a displacement capacity and a CPD satisfying the minimum requirements specified by AISC 341-10 [40] (interstorey drift ratio $\geq 2 \%$ and $C P D \geq 200$ ).

Figs. (4a and 4b) show the axial deformation (namely lengthening and shortening, respectively) of the core of BRB prototypes at drift ratios ranging within $\pm 2 \%$. In this range, no significant damage to BRBs was observed. When the drift ratio increased from $2 \%$ to $3 \%$, local damage of the casing started to become apparent. Separation of the two parts constituting the casing was due to the contact forces generated by the buckled core plate (Fig. 4d). At an interstorey drift ratio of $+3 \%$ both $\mathrm{BRBs}$ reached their maximum deformation capacity in compression (Fig. 4c), while separation between parts of the casing became large (Fig. 4e).

\section{FINITE ELEMENT ANALYSIS}

\subsection{Finite Element Model of the BRB Prototype}

Finite Element Analyses (FEAs) were carried out in order to assess the influence of a few design parameters on the performance of the novel all-steel BRBs. The numerical models were implemented and analysed with the software ABAQUS v.6.10 [41]. Fig. (5) shows schematically the FE model. Considering its symmetry, the model included only one-half of the BRB with the appropriate restraints for the BRB mid-length joints. Nodes belonging to cross-sections at the ends of the specimen were slaved to reference points: $\mathrm{RP}-\mathrm{A}$ is the master node at the brace end connection and RP$\mathrm{B}$ is the master node at the brace mid-length section. The loading history was controlled by the axial displacement at RP-A under quasi-static loading conditions.

Steel yielding and hardening behaviour were modelled using the von-Mises yield criteria with associated flow rule and combined nonlinear isotropic and kinematic strain hardening. Results from tests on materials, carried out within the experimental activity described in previous sections, allowed to define the stress-strain relationship in the simulations. Available data from cyclic tests on carbon steel [42] allowed calibrating the steel cyclic hardening behaviour.

Initial geometrical imperfections were simulated by means of the first buckling mode scaled in such a way that 


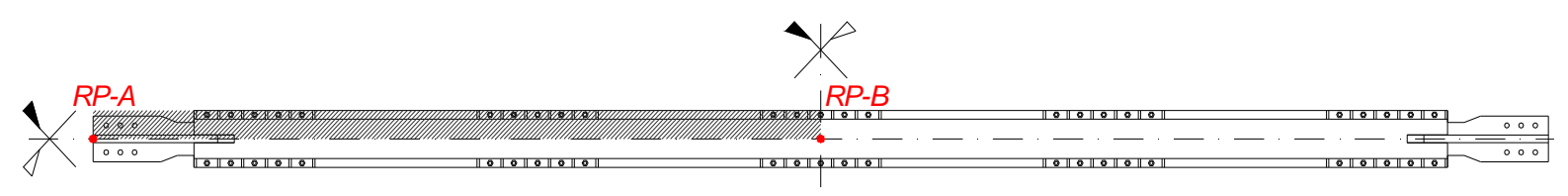

Fig. (5). Schematics of the FE model.

the maximum initial displacement amplitude was 1/3000 of the core length [31]. The large strain, large displacement option allowed consideration of the geometric non-linear behaviour.

The core, the casing and the bolts were modelled through the eight-node solid element C3D8R. Bolt clamping forces were introduced in the model using the bolt load function, with the load applied onto the internal transverse surface at the mid length of the bolt shank. Finite-sliding interaction with a Coulomb friction coefficient of 0.3 modelled contacts between the steel core and the casing inner surface. This value of the coefficient of friction is suitable for rough and dry surfaces [43] such as those of the tested specimens. The model allows separation of the interface and no compression penetration.

Fig. (6) shows core and casing deformations under increasing axial displacements corresponding to the interstorey drift ratios $(\theta)$ experimentally applied to the building equipped with BRB prototypes. Comparison of (Figs. 6 and 4) shows that the FE model reproduces the damage pattern as observed in the physical tests. Indeed, 12 half-waves along the half core length are observed after yielding and strain hardening of the $\mathrm{BRB}$ core, in both the model and the test. The numerical analysis showed no global buckling up to the axial displacement corresponding to the maximum interstorey drift ratio experienced in the test, while significant local flexural deformations of the casing occurred.

Fig. (7a) depicts the BRB cyclic response. The maximum difference between compression and tension resistance is approximately $22 \%$. The saw-teeth shape of the numerical cyclic response curve is due to thrust and friction forces developing at contact zones between the core and the casing, as also recognized in other numerical studies [44]. This behaviour becomes more evident during the curling up in compression of the core plate, but it appears also at force reversal from compression to tension because of contact still acting before core straightening in tension.

Fig. (7b) depicts a comparison between the BRB response and the response of an ideal equivalent onedimensional steel strut, i.e., a truss element that cannot buckle and without interaction with the casing. Such a comparison clearly highlights that the effects of core-to-casing interactions are more important in compression than they are in tension. These effects are strictly dependent on the BRB details, such as the core-to-casing clearance and the stiffness of the casing components. The transverse stiffness of the casing is strongly influenced by the number of bolts. Therefore, the influence of such parameters on BRB response is analysed in the following sections.

\subsection{Influence of Core-to-Casing Clearance}

This section examines the effect of different values of the core-to-casing clearance $(s)$ on the BRB response. Values of $s$ equal to $0 \mathrm{~mm}, 0.5 \mathrm{~mm}, 1 \mathrm{~mm}, 2 \mathrm{~mm}$, and $3 \mathrm{~mm}$ were examined. It is noted that the reference prototype was designed and fabricated with a nominal clearance of $2 \mathrm{~mm}$ (Fig. 2). Fig. (8) shows the results of this numerical investigation. For $s$ in the range $[0 \mathrm{~mm}-1 \mathrm{~mm}]$ overall BRB buckling is predicted to occur prior to the full exploitation of the core-tocasing relative axial displacement capacity (Fig. 8a). For a clearance in the range [2 $\mathrm{mm}-3 \mathrm{~mm}$ ], the device exhibits a more ductile behaviour with local flexural deformations of the two parts constituting the casing (Fig. 8b). In such a case the collapse modes predicted by FEAs (Fig. 8b) are in good agreement with those experimentally observed (Fig. 4d).

Besides, the FEA results showed that the compression post-yield stiffness significantly varies with $s$ (Fig. 8c). The smaller is the clearance and the larger is the post-yield stiffness in compression. For the examined prototype, it is advisable to select the size of $s$ larger than $1 \mathrm{~mm}$ not only to avoid the overall buckling failure but also to limit the post-yield stiffness, which could be detrimental in terms of forces transmitted to structural elements connected to the BRB. On the other hand, excessively large gaps (e.g., $s \geq 3$ ) can impair the dissipative capacity of the device, because of significant geometrical effects which could lead to localized large plastic strains in the core plate.

\subsection{Influence of Bolt Spacing}

In order to evaluate the influence of the number of casing connections, namely the bolt spacing along the casing, two cases were examined: casing with continuous bolting (CB) and with spaced bolting (SB) as in the case experimentally tested. Fig. (9a) shows the core deformations for the CB option, while Fig. (9b) illustrates results for the SB case. It is observed that in the CB case the buckling waves tend to localize at the core end in the air gap zone. When this phenomenon occurs, the buckled core plate tends to interlock in the air gap zone, thus transferring the axial load to the casing as testified by the larger post-yield stiffness of the response curve in case of a $\mathrm{CB}$ connection compared to the $\mathrm{SB}$ case (Fig. 9c).

FEAs clearly shows that allowing the formation of multiple waves along the core length avoids the transmission of appreciable axial forces to the casing; contact forces acting on upper and lower encasing walls will approximately balance each other, avoiding the overall buckling of the brace, as also observed by other researchers [33, 45].

\subsection{Compression-to-Tension Strength Ratio}

The ratio of compression to tension strength is frequently denoted by the symbol $\beta$, which is also referred as the compression strength adjustment factor [40]. This parameter is very important for the design of non-yielding parts of BRBs. Available experimental results show that $\beta$ depends on the 


\section{buckling mode 1 (initial geometrical imperfection $=1 / 3000 L_{c}$ ):}

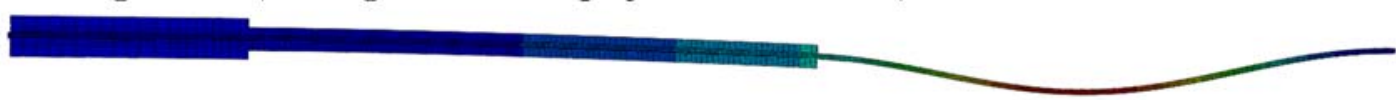

\section{$\theta=0.15 \%$ (yielding):}

\section{$\theta=3 \%$ (maximum demand):}

Fig. (6). BRB model response: core and casing deformations.

a)

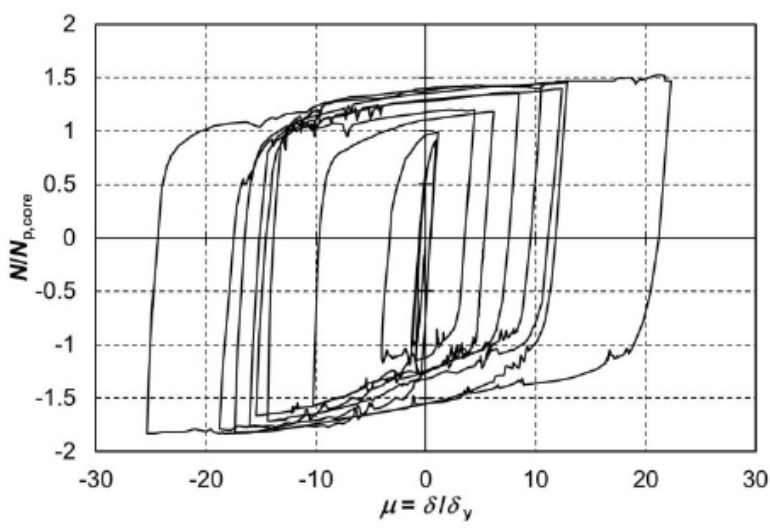

b)

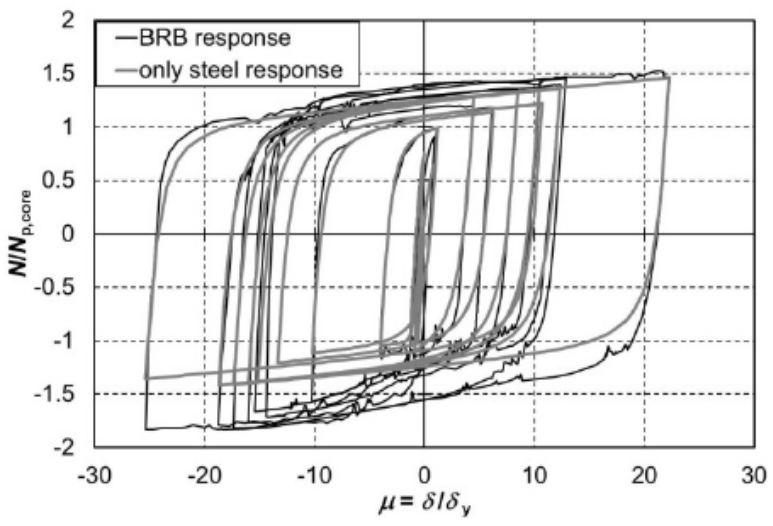

Fig. (7). BRB model response: cyclic response under the loading protocol as used in the experimental test.

a)

b)

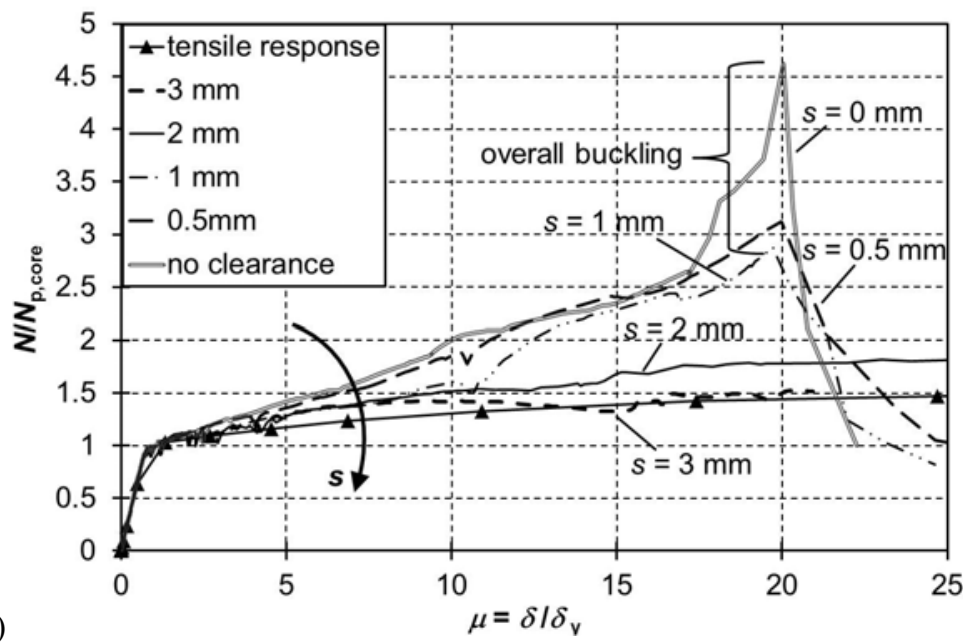

Fig. (8). Influence of core-to-casing clearance: a) Overall buckling mode; b) Ductile failure mode of the casing; c) Response curves. 


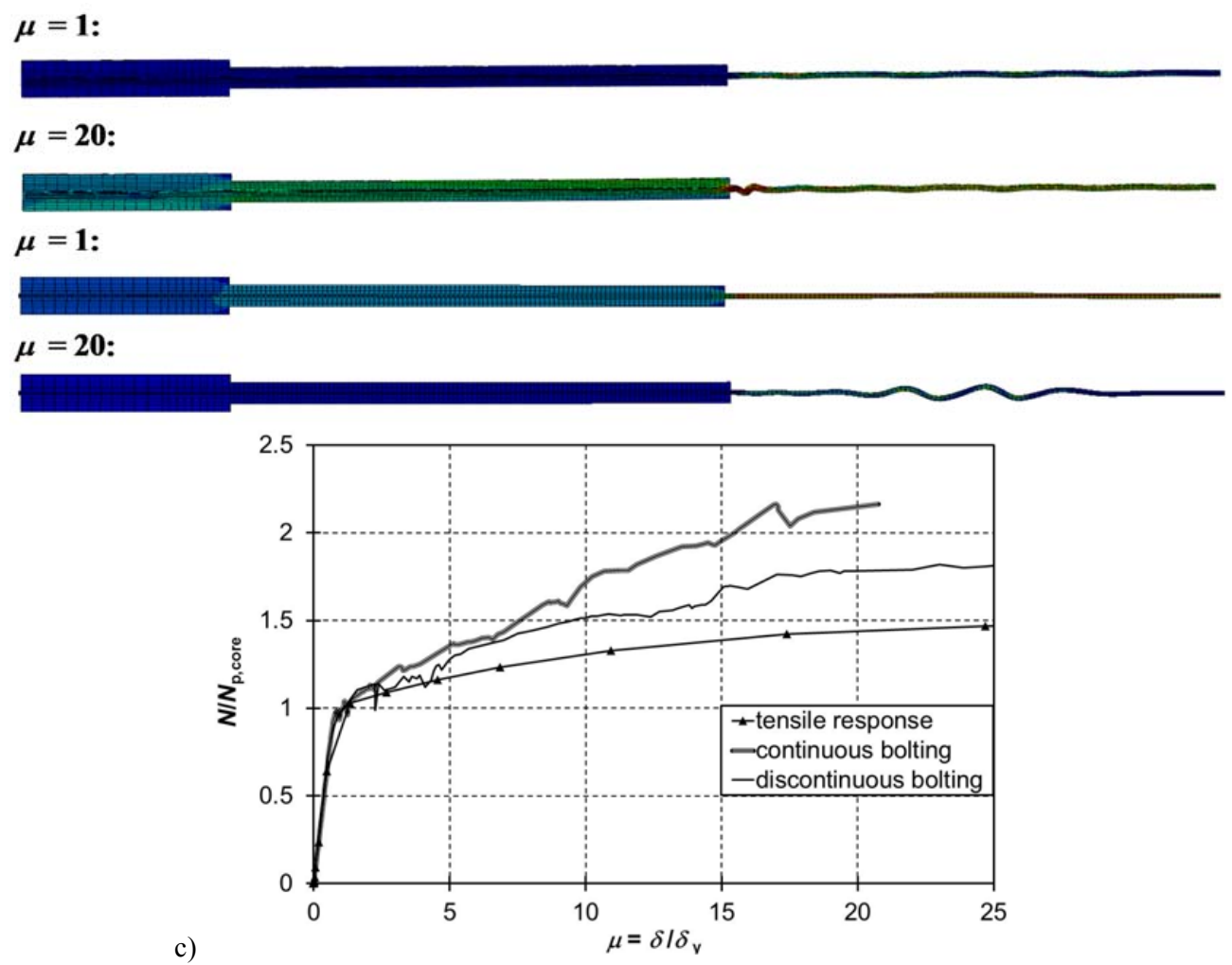

Fig. (9). Influence of bolt spacing along the casing length.

ductility level imposed to the brace and the detailing of the device, namely the core shape, the core-to-casing clearance, the air gap size, the shape and the stiffness of the casing.

Tremblay et al., [30] tested four all-steel BRBs having the casing made of hollow steel tubes with core-to-casing clearance ranging from $0.58 \mathrm{~mm}$ to $1.52 \mathrm{~mm}$ and found a $\beta$ factor varying in the range 1.11 to 1.27 for a ductility demand $\mu=5$. Zhao et al., [46] tested a set of all-steel BRBs having the steel core made of four steel angle profiles arranged to form a non-welded cruciform shape and having the casing composed by two external angle profiles longitudinally welded to form a tube. These BRBs were made with core-to-casing clearance ranging from $0.93 \mathrm{~mm}$ to $2.42 \mathrm{~mm}$ and corresponding $\beta$ factors were found in the range 1.10 to 1.26 for different level of ductility demand. In particular, the minimum $\beta$ occurred at $\mu=11.8$ for the specimen with $s=1.12 \mathrm{~mm}$, while the maximum value of $\beta$ occurred for the specimen having $s=1.08 \mathrm{~mm}$ at $\mu=16.8$. Eryasar and Topkaya [32] carried out tests on all-steel BRBs with different casing connections (hand-tightened bolted casings, welded casings and snug-tightened bolted casings) and observed significant differences in terms of $\beta$ factors (from 1.1 to 1.35 for $\mu=10$ ). Using linear regression analysis of their experimental results, Eryasar and Topkaya [32] derived the following predictive equation:

$$
\beta=C \cdot(\bar{\varepsilon})+1
$$

where $\bar{\varepsilon}$ is the normalized average plastic strain, which might be expressed as a function of the ductility as $\bar{\varepsilon}=(\mu-1) ; C$ is a coefficient depending on the type of casing details and was set equal to $0.008,0.0132$, and 0.0298 for hand-tightened bolted casing, welded casing and snugtightened bolted casings, respectively.

Fig. (10a) shows variations of the compression strength adjustment factor as function of the ductility demand, for given values of $s$ given in the legend of the plots. Consistently to what observed in Section 3.2 in terms of post-yield stiffness, in the examined BRBs the $\beta$ factor decreases for larger sizes of $s$.

Based on multiple regressions of the numerical data shown in Fig. (10a), the following equation is proposed to predict $\beta$ as function of $\mu$ and $s$ :

$$
\beta=a \cdot \mu^{2}+b \cdot \mu \cdot \operatorname{Exp}\left(-\left(s-s_{o}\right)^{c}\right)+d
$$

where $a=-0.0004, b=0.0206, c=0.2$ and $d=0.9786$, while $s_{\mathrm{o}}$ is the reference clearance assumed equal to 2 .

As it can be observed in Fig. (10), the tendency of the proposed function is close to linearity. However, a linear equation is less accurate than the proposed Eq. (2), needing also the calibration of coefficients for each different size of $s$. On the contrary, the proposed Eq. (2) is more efficient, because the calibrated coefficients are only dependent of the device typology, thus allowing to calculate the $\beta$ factor for any $s$.

The comparison between the predictions given by Eq. (1) and (2) and the numerical results are plotted in Fig. (10b) through Fig. (10f). Although Eq. (1) was derived for a different type of $\mathrm{BRB}$, it is included in the comparison in order to check the possibility to extend its application to the case study presented here. In particular, Eq. (1) was applied 
a)
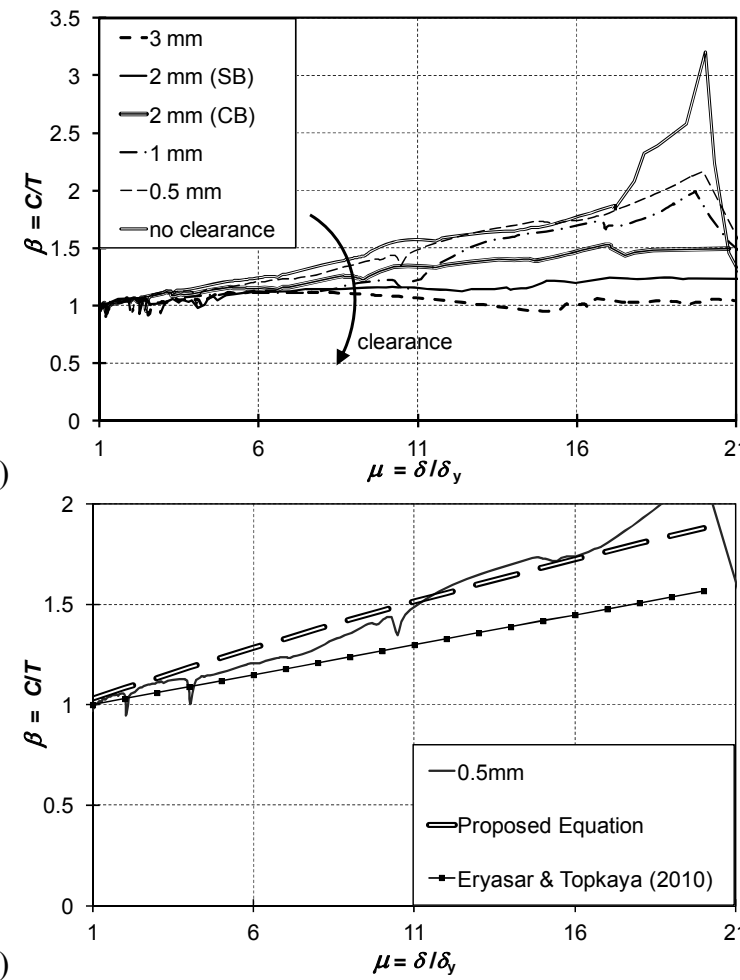

c)

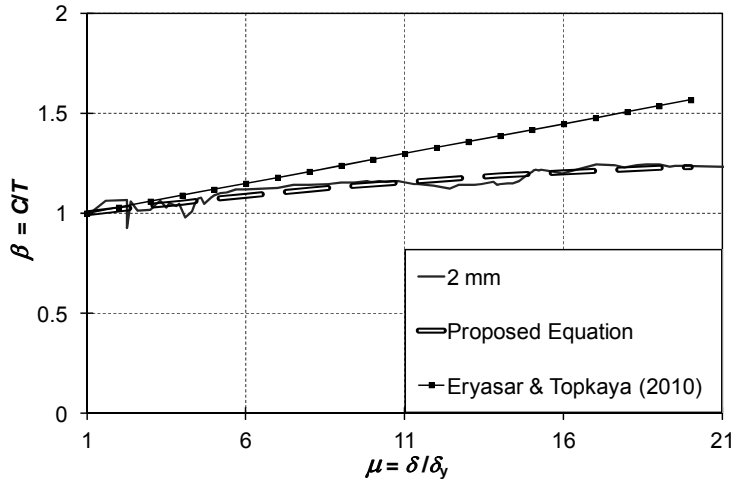

b)
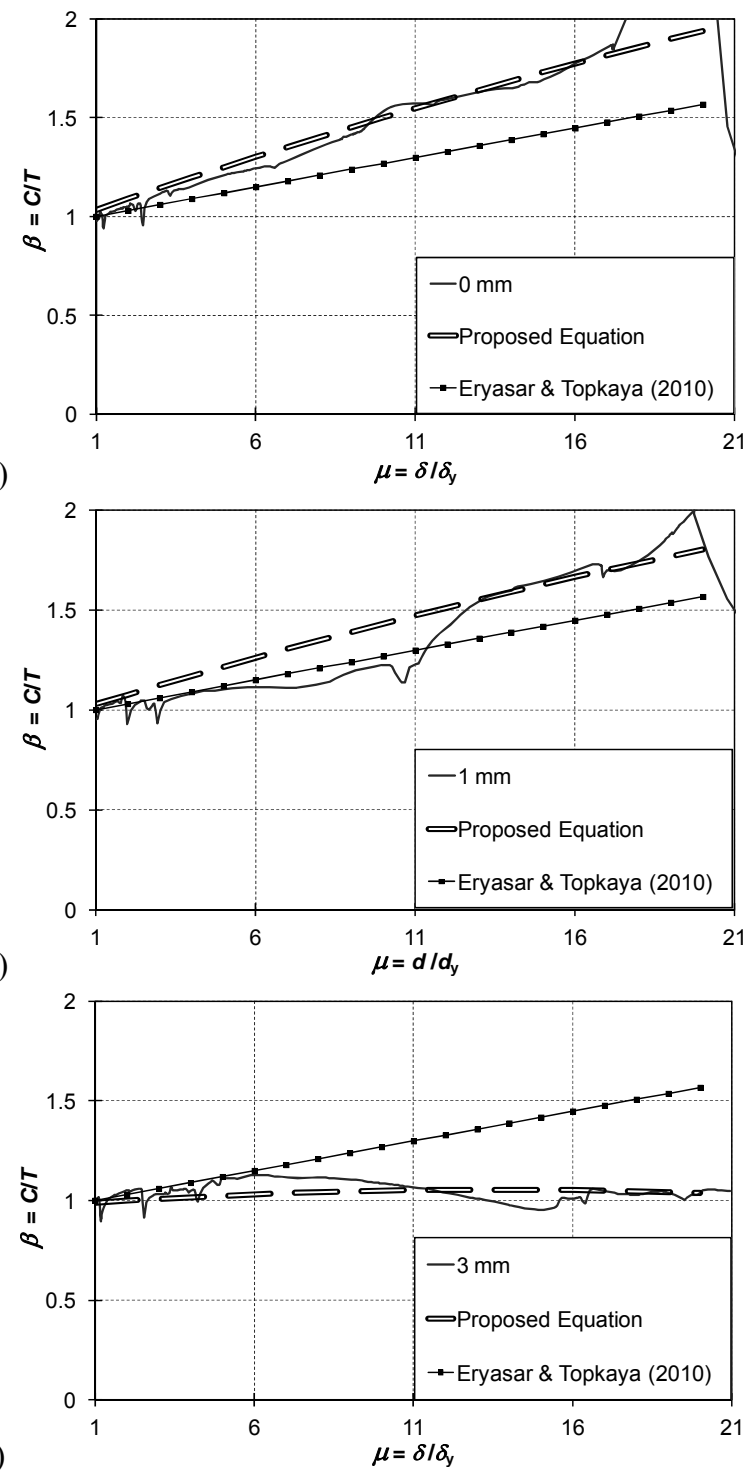

Fig. (10). Evaluation of compression strength adjustment factors $\beta$.

considering the case of snug-tightened bolted casing, which applies to the tested cases. In addition, in order to quantify the correlation to numerical results, Table 1 reports the Pearson index $(r)$ and standard error (Std.Err) of the predictions by Eq. (1) and (2).

Fig. (10) and Table 1 demonstrate that Eq. (2) matches the FEA results better than Eq. (1) (larger $r$ and smaller Std.Err.) except for $s=1 \mathrm{~mm}$. In this case Eq. (2) overestimates the $\beta$ factor up to a ductility $\mu=12$, while for larger ductility the differences between the analytical predictions and the FEA results are negligible. For $s=3 \mathrm{~mm}$ both equations lead to the largest error, underestimating $\beta$ up to a ductility $\mu=11$ and overestimating it for larger ductility.

The comparison with Eq. (1) highlights that the accuracy of the predictive formula is strictly dependent on the geometrical details of the device.

\subsection{Core-to-Casing Interactions}

Consistently with experimental test results, FEAs showed that the buckling wave amplitudes are not uniform along the

BRB core length. Two different aspects cause this phenomenon: 1) friction stresses between the core and the casing; 2) variation of flexural stiffness of the casing walls because of the discontinuous bolting. Owing to friction stresses, the core axial deformations localize at either the core ends, for clearances in the range $[0 \mathrm{~mm}-1 \mathrm{~mm}]$, or at the middle of the core, for clearances larger than $1 \mathrm{~mm}$.

Chou and Chen [31] and Genna and Gelfi [47, 48] provided analytical equations to calculate half-wave length $\left(L_{0}\right)$ assuming a sinusoidal deformation shape and the use of theory of elastic-plastic buckling for squat columns. In particular, Genna and Gelfi [48] highlighted that the distribution of waves is very difficult to be accurately predicted because it depends on the loading history, friction stresses and local geometrical effects. All these factors are strictly related to the type of BRB. In particular, the analytical equations provide a constant $L_{\mathrm{o}}$ along the core span (stationary regime) for each level of axial shortening, while experimental and numerical tests showed that $\left(L_{\mathrm{o}}\right)$ varies. In any case, FEAs showed that if $L_{\mathrm{o}}$ is at a minimum, then the corresponding 
Table 1. Statistical parameters of Eq. (1) and (2).

\begin{tabular}{|c|c|c|c|c|c|c|c|c|c|c|}
\hline & \multicolumn{2}{|c|}{$\boldsymbol{s}=\mathbf{0 ~ \mathbf { ~ m m }}$} & \multicolumn{2}{c|}{$\boldsymbol{s}=\mathbf{0 . 5} \mathbf{~ m m}$} & \multicolumn{2}{c|}{$\boldsymbol{s}=\mathbf{1} \mathbf{~ m m}$} & \multicolumn{3}{|c|}{$\boldsymbol{s}=\mathbf{2} \mathbf{~ m m}$} & \multicolumn{2}{c|}{$\boldsymbol{s}=\mathbf{3} \mathbf{~ m m}$} \\
\hline & $\boldsymbol{r}$ & Std.Err & $\boldsymbol{r}$ & Std.Err & $\boldsymbol{r}$ & Std.Err & $\boldsymbol{r}$ & Std.Err & $\boldsymbol{r}$ & Std.Err \\
\hline \hline Eq. (1) & 0.9690 & 0.0766 & 0.8414 & 0.0710 & 0.8446 & 0.0866 & 0.9030 & 0.0334 & 0.1042 & 0.0975 \\
\hline Eq. (2) & 0.9703 & 0.0750 & 0.9807 & 0.0647 & 0.9643 & 0.0971 & 0.9346 & 0.0276 & 0.5130 & 0.0387 \\
\hline
\end{tabular}

core-to-casing contact forces are maxima. Hence, in the following the numerical results in terms of contact forces refer the minimum value of $L_{0}$.

In order to investigate the possibility to predict the local response using analytical equations for different BRB configurations, the predicted $L_{\mathrm{o}}$ are compared with those obtained from FEAs.

Fig. (11a) depicts the variation of $L_{\mathrm{o}}$ with the size of the clearance, for $\mu=20$ (corresponding to $\theta=3 \%$ in the experimental test). The experimental and numerical outcomes presented in [47-48] showed that the half-wave length reduces as far as the clearance is increased. Fig. (11a) shows that for $s$ ranging from $0 \mathrm{~mm}$ to $0.5 \mathrm{~mm}$ there is an increase of the half-wave length, while for $s$ increasing from $1 \mathrm{~mm}$ to $3 \mathrm{~mm}$ then $L_{\mathrm{o}}$ actually decreases. In Fig. (11a), for $s=2 \mathrm{~mm}$ the value of $L_{\mathrm{o}}$ experimentally measured and those obtained from FEAs for both a casing with continuous bolting (CB) and a spaced bolting (SB) is plotted. As it can be observed, the value of $L_{\mathrm{o}}$ given by the FEA for the SB configuration is very close to that experimentally measured, thus confirming the validity of the numerical simulation. The comparison between $\mathrm{SB}$ and $\mathrm{CB}$ configurations shows that $L_{\mathrm{o}}$ is smaller in the latter case. Analytical predictions, are also illustrated in Fig. (11a). The equation given by Chou and Chen [31] largely underestimates $L_{0}$ in all cases, while the equation given by Genna and Gelfi [48] is closer to the FEA results for $s$ ranging from $1 \mathrm{~mm}$ to $3 \mathrm{~mm}$. In addition, for $s=2 \mathrm{~mm}$ the model by Genna and Gelfi [48] slightly underestimates both experimental and numerical results for the SB case, while it overestimates the numerical results for the $\mathrm{CB}$ configuration.

Chou and Chen [31] and Genna and Gelfi [48] provided analytical equations allowing also the evaluation of transverse contact forces $(Q)$ as a function of $L_{\mathrm{o}}$ based on the fail-

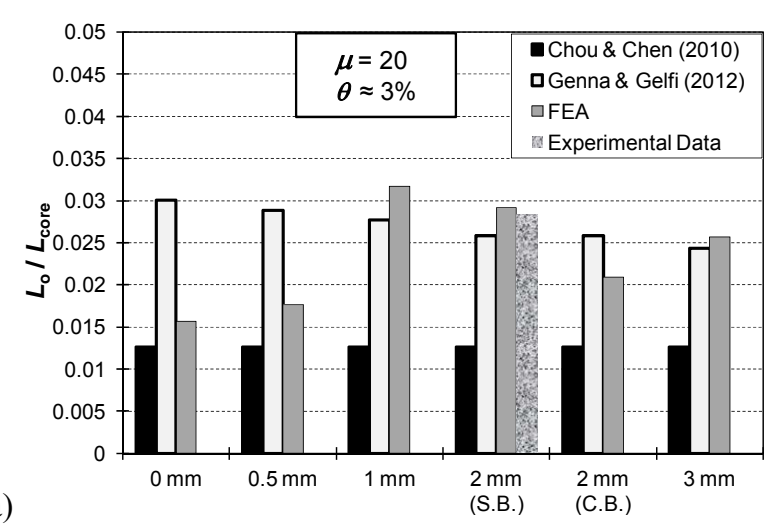

a)

b)

Fig. (11). Analytical vs. numerical prediction: a) Local buckling half-wave length; b) Contact forces developing at core-to-casing interface. ( $\mathrm{SB}=$ Spaced Bolting; $\mathrm{CB}=$ Continuous Bolting).

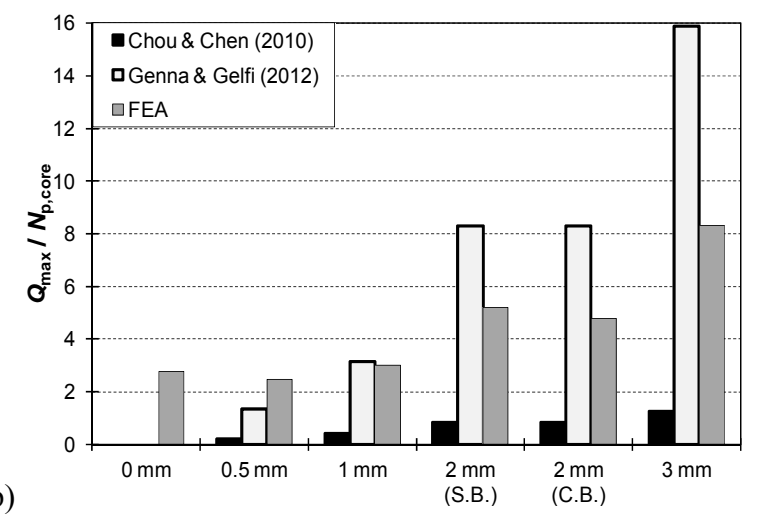

ure mode described in Fig. (12). Both models assume a sinusoidal buckled shape of the core, but significant differences exist between the two proposed models. The model by Chou and Chen [31] provides the thrust forces as a function of the core-to-casing clearance, the wavelength and the maximum axial strength of the BRB. The formulation by Genna and Gelfi [48] also includes the ductility, the influence of loading protocol and friction forces, verifying the analytical model against experience on BRBs different from those examined in the present study. Fig. (11b) plots the peak thrust force $\left(Q_{\max }\right)$ normalized by the core plastic strength $\left(N_{\mathrm{p}, \mathrm{core}}\right)$ obtained from FEAs and analytical predictions for comparison purposes. The two analytical models give zero contact forces in case of no clearance, while FEAs showed core buckling in the air gap zone and consequent contact forces developing in that zone. Fig. (11b) shows that thrust forces calculated according to Chou and Chen [31] underestimates FEAs, while those calculated according to Genna and Gelfi [48] underestimate numerical results for clearances smaller than $1 \mathrm{~mm}$ and overestimate them for clearances larger than $1 \mathrm{~mm}$.

It is worth noting that FEA results depicted in Fig. (11) show that the local response of BRB is highly sensitive to the geometrical details. Therefore a specific calibration of analytical formulations is required when changing the type of BRB. These outcomes are in line with those observed by Genna and Gelfi [48], who conclude that the analytical estimate of the thrust forces could be affected by errors of the order of $\pm 100 \%$, especially for small demand and large clearance, because the actual buckled shape of the core is far from being periodic and significant geometrical effects could occur. Anyway, the trend of $Q$ with the applied displacement is reasonably approximated, as also confirmed by comparing the analytical predictions by the model in [48] with the output of FEAs. 


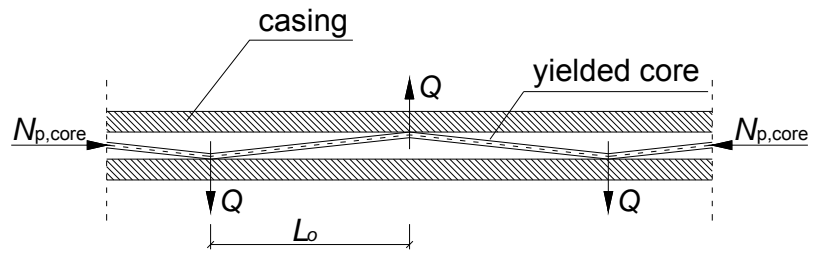

Fig. (12). Core-to-Casing interactions.

In order to develop design charts for the examined BRB typology, a novel equation is proposed to provide a more refined prediction of thrust forces. The proposed equation was obtained by means of multiple regression of the numerical results as function of the ductility demand $(\mu)$ and the size of core-to-casing clearance $(s)$. It is made of two terms as follows:

$Q=f(\mu) \cdot g(s)=\left(\begin{array}{l}0.0005 \mu^{3}-0.0055 \mu^{2}+ \\ 0.1382 \mu+0.1013\end{array}\right) \cdot(0.4913 s+0.1503)$

where the first term provides the shape of the variation of $Q$ with $\mu$, while the second term scales this shape based on the value of $s$. Indeed, numerical results showed that the variation of $Q$ with $\mu$ is very similar for all the examined values of $s$, as also confirmed by the analytical model presented in [48]. In order to clarify this aspect, a more comprehensive comparison between such model predictions and FEA results is provided in Fig. (13). The proposed Eq. (3) closely fits the numerical response curves. Only in case of $s=1 \mathrm{~mm}$ Eq. (3) slightly underestimates the FEA results (Fig. 13b). The model proposed by Genna and Gelfi [48] gives better predictions for small clearances. In particular, for $s=0.5 \mathrm{~mm}$ it gives a good estimate of FEA results up to a ductility of about 7.5 (Fig. 13a). For larger ductility demand, the analytical model underestimates the numerical results because of the concentration of damage in the casing and the interactions between the deformed core and the damaged casing (not accountable by the analytical model). For $s=1 \mathrm{~mm}$, a very good matching of numerical results is observed (Fig. 13b). For clearances of either $2 \mathrm{~mm}$ or $3 \mathrm{~mm}$, the analytical model by [48] overestimates thrust forces at all levels of ductility demand. The overestimation appears to be rather large, the ratio of predicted-to-computed values being almost always equal to about 2 .

It should be noted that Eq. (3) is calibrated on FEA data obtained on a specific type of BRB. Since the mechanism of force transmission from core to casing is strongly dependent on the geometrical details and it is strongly nonlinear, Eq. (3) could lead to a misestimate of $Q$ forces for BRB configurations different from that examined in this paper. In the Author's opinion this issue needs a further investigation.

\section{CONCLUSION}

This paper has shown and discussed the main results of a numerical study devoted to analyse the behaviour of "allsteel" dismountable buckling restrained braces specifically designed to improve the seismic capacity of existing RC buildings. The peculiarity of the system is the small transverse size allowing to hide the devices inside the two facades of the typical masonry claddings used for RC buildings. To obtain such a small transverse size, the casing was conceived as made of two built-up Omega shapes. To make the system dismountable, bolted connections joined the two Omega shapes.

Finite element analyses allowed to characterize the response of the proposed devices and to describe the complex interaction developing between the core and the casing.

The numerical simulations allowed examining (i) effects of core-to-casing clearance, (ii) influence of casing connec-
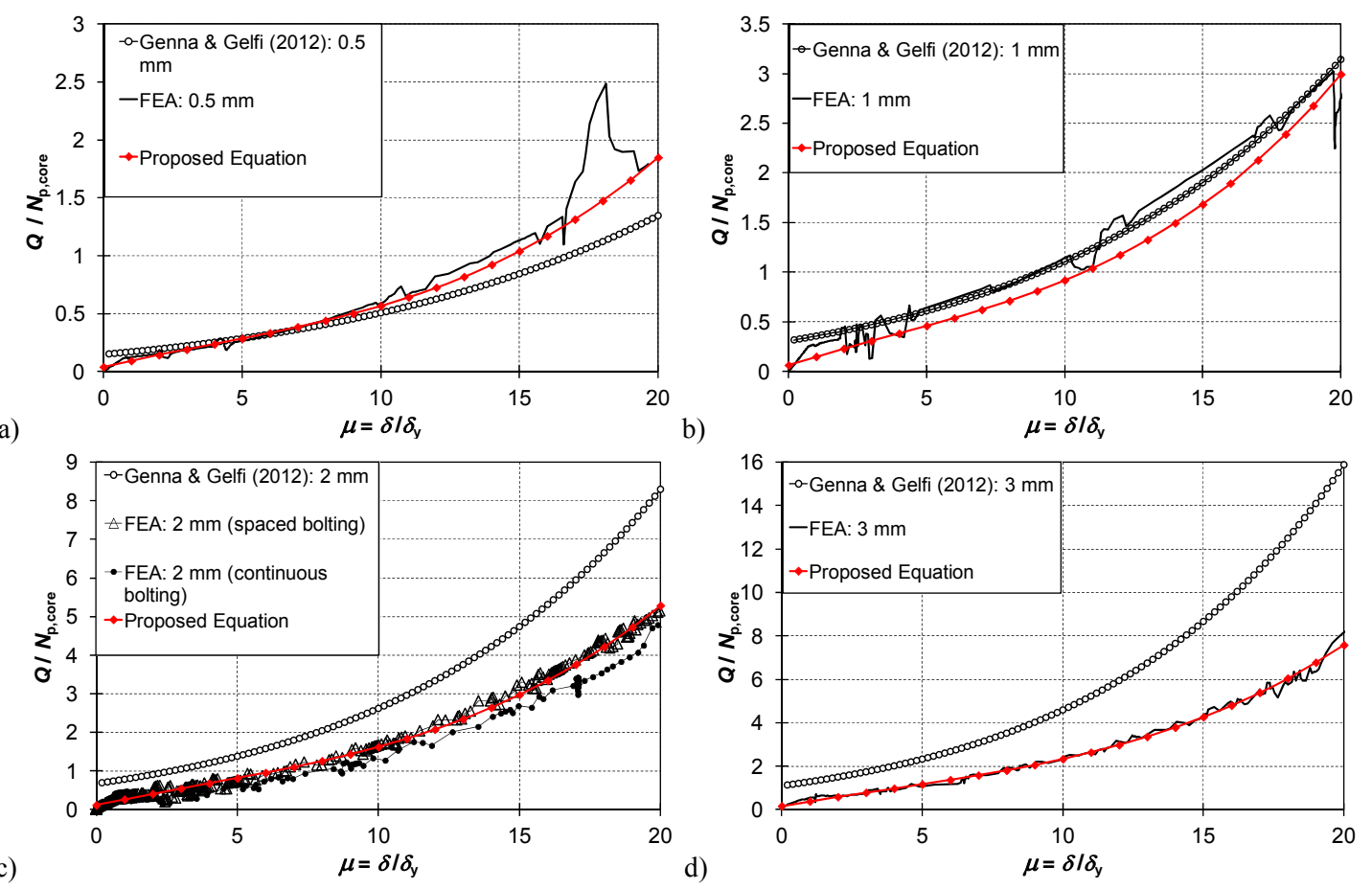

Fig. (13). Analytical vs. numerical prediction: evolution of maximum thrust forces. 
tions, (iii) difference between compression and tension force capacity, (iv) peak thrust forces acting on the casing after core local buckling. The following conclusions are drawn:

1. The clearance size affects the intensity of contact forces, both transverse ("thrust forces") and longitudinal friction forces. The latter induce axial compression loads in the casing when compression displacements are applied.

2. The smaller is the clearance, the larger is the compression force transferred from the core to the casing. For a clearance in the range $[0 \mathrm{~mm}-1 \mathrm{~mm}]$, the tested BRBs exhibited premature overall buckling, while for larger clearances bulging of the casing was observed allowing the development of larger displacements.

3. The core-to-casing thrust forces $Q$ increase with the coreto-casing clearance. For the examined BRB, $Q$ could vary from 2 to 8 times the core yield strength for clearances in the range $[0 \mathrm{~mm}-3 \mathrm{~mm}]$, at a ductility demand equal to 20. The effectiveness of available analytical models $[31,48]$ to predict the thrust forces $Q$ was also investigated. The comparison between FEAs and analytical results showed that the model presented in [31] strongly underestimate the contact forces, while the model given in [48] underestimates the contact forces for clearances in the range $[0 \mathrm{~mm}-1 \mathrm{~mm}]$ and overestimates them for larger clearance. Based on the numerical data, a novel equation has been proposed to predict the maximum value of $Q$.

4. Both the experimental and numerical results showed the need of further investigation on the mechanism of formation of thrust forces and the transmission of axial force from the core to the casing.

5. If bolted connections are distributed over the whole length, then the transverse stiffness of the casing increases so much that the core buckling waves localize in the air gap zone. When this phenomenon occurs, axial forces tend to be transmitted from the core to the casing.

6 . For the tested prototype, the compression strength adjustment factors $\beta$ (namely the ratio of maximum compressive force to maximum tensile force) satisfies the AISC 341-10 [40] requirement, being equal to 1.22 , less than 1.3. The numerical results show that for clearance $(s)$ increasing from $0 \mathrm{~mm}$ to $3 \mathrm{~mm}$, the $\beta$ factor could vary in the range $[1.05,1.50]$ for a ductility $\mu=10$ and within the range $[1.13,3.20]$ for $\mu=20$. Based on simulation data, an equation is provided to predict $\beta$ as function of ductility demand and core-to-casing clearance.

\section{CONFLICT OF INTEREST}

The authors confirm that this article content has no conflict of interest.

\section{ACKNOWLEDGEMENTS}

Declared none.

\section{REFERENCES}

[1] A.B. Climent, "Influence of hysteretic dampers on the seismic response of reinforced concrete wide beam-column connections", Engineering Structures, vol. 28, pp. 580-92, 2006.
[2] F.M. Mazzolani, G. Della Corte, and M. D’Aniello, "Experimental analysis of steel dissipative bracing systems for seismic upgrading", Journal of Civil Engineering and Management, vol. 15, pp. 7$19,2009$.

[3] M. D'Aniello, G. Della Corte, and F.M. Mazzolani, "Seismic Upgrading of RC Buildings by steel eccentric braces: Experimental Results $v s$. Numerical Modeling", In: Proceedings of STESSA Conference 2006, Japan, pp. 14-17, 2006.

[4] E. Barecchia, M. D'Aniello, G. Della Corte, and F.M. Mazzolani, "Eccentric bracing in seismic retrofitting: From full scale tests to numerical FEM analysis". In: Proceedings of International Conference in Metal Structures - Steel - A New and Traditional Material for Building; Poiana Brasov; Romania, 2006.

[5] G. Della Corte, M. D'Aniello, and F.M. Mazzolani, "Inelastic response of shear links with axial restraints: Numerical vs. analytical results". In: Proceedings of $5^{\text {th }}$ International Conference on $\mathrm{Ad}$ vances in Steel Structures, ICASS 2007.

[6] H. El-Sokkary, and K. Galal, "Analytical investigation of the seismic performance of RC frames rehabilitated using different rehabilitation techniques", Engineering Structures, vol. 31, pp. 195566, 2009.

[7] C. Durucan, and M. Dicleli, "Analytical study on seismic retrofitting of reinforced concrete buildings using steel braces with shear link", Engineering Structures, vol. 32, pp. 2995-3010, 2010.

[8] J.A. Oviedo-Amezquita, M. Midorikawa, and T. Asari. "Earthquake response of ten-story story drift-controlled reinforced concrete frames with hysteretic dampers", Engineering Structures, vol. 32, pp. 1735-46, 2010.

[9] G. Della Corte, M. D'Aniello, and R. Landolfo, "Analytical and numerical study of plastic overstrength of shear links", Journal of Constructional Steel Research, vol. 82, pp. 19-32, 2013.

[10] G. De Matteis, A. Formisano, F.M. Mazzolani, and S. Panico, "Design of low-yield metal shear panels for energy dissipation". In: Proceedings of the Final Conference of COST Action C12, Innsbruck (Austria), pp. 665-675, 2005.

[11] A. Formisano, A. G. De Matteis, and F.M. Mazzolani, "Numerical and experimental behaviour of a full-scale RC structure upgraded with steel and aluminum shear panels", Computers and Structures, vol. 88, no. 23-24, pp. 1348-60, 2010.

[12] A.P. Brown, I.D. Aiken, and F.J. Jafarzadeh, "Buckling restrained braces provide the key to the seismic retrofit of the wallace $f$. bennett federal building", Modern Steel Construction, 2001.

[13] A. Wada, and M. Nakashima, "From infancy to maturity of buckling restrained braces research", In: Proceedings of the $13^{\text {th }}$ World Conference on Earthquake Engineering, Vancouver: Canada, CDROM: paper no. 1732, 2004.

[14] K. C. Tsai, J.W. Lai, Y. C. Hwang, S. L. Lin, and Y. T. Weng, "Research and application of double-core buckling restrained braces in Taiwan", In: Proceedings of the 13th World Conference on Earthquake Engineering, Canada, CD-ROM: paper no. 2179, 2004

[15] Q. Xie, "State of the art of buckling-restrained braces in Asia", Journal of Constructional Steel Research, vol. 61, pp. 727-48, 2005.

[16] R. Antonucci, F. Balducci, M.G. Castellano, and F. Donà, "Precasted RC buildings with buckling restrained braces: the example of the new building of the faculty of engineering in ancona", In: Proceedings of the $2^{\text {nd }}$ International Fib Congress, Naples (Italy), 2006.

[17] Dasse Design Inc., "Cost advantages of buckling restrained braced frame buildings", Technical report, www.dasse.com, May 27, 2007.

[18] M. Bosco, and E. M. Marino, "Design method and behavior factor for steel frames with buckling restrained braces", Earthquake Engineering \& Structural Dynamics, vol. 42, pp. 1243-63, 2013.

[19] M. D'Aniello, F. Portioli, and R. Landolfo, "Modelling issues of steel braces under extreme cyclic actions". In: Proceedings of COST-C26 Final Conference, Naples, 16-18 September 2010.

[20] M. D'Aniello, G. La Manna Ambrosino, F. Portioli, and R. Landolfo, "Modelling aspects of the seismic response of steel concentric braced frames", Steel and Composite Structures, An International Journal, vol. 15, pp. 539-566, 2013.

[21] M. D'Aniello, G. La Manna Ambrosino, F. Portioli, and R. Landolfo, "The influence of out-of-straightness imperfection in Physical-Theory models of bracing members on seismic performance assessment of concentric braced structures", The Structural Design of 
Tall and Special Buildings, 2014 (published online 20April 2014). DOI: $10.1002 /$ tal.1160.

[22] A. Longo, R. Montuori, and V. Piluso, "Failure mode control of Xbraced frames under seismic actions", Journal of Earthquake Engineering, vol. 12, no. 5, pp. 728-59, 2008.

[23] A. Longo, R. Montuori, and V. Piluso, "Plastic design of seismic resistant V-braced frames", Journal of Earthquake Engineering, vol, 12, no. 8, pp. 1246-66, 2008.

[24] M.T. Giugliano, A. Longo, R. Montuori, and V. Piluso, "Plastic design of CB-frames with reduced section solution for bracing members", Journal of Constructional Steel Research, vol. 66 no. 5, pp. 611-21, 2010.

[25] M.T. Giugliano, A. Longo, R. Montuori, and V. Piluso, "Seismic reliability of traditional and innovative concentrically braced frames", Earthquake Engineering and Structural Dynamics, vol. 40, no. 13, pp. 1455-74, 2011

[26] E.M. Marino, "A unified approach for the design of high ductility steel frames with concentric braces in the framework of Eurocode 8”. Earthquake Engineering and Structural Dynamics, vol. 43, pp. 97-118, 2014.

[27] C. Castaldo, V. Macillo, A. Formisano, L. Fiorino, B. Faggiano, and F. M. Mazzolani, "Evaluation of the Italian seismic code for the design of concentrically v-braced steel structures", In: Proceedings of $7^{\text {th }}$ European Conference on Steel and Composite Structures (EUROSTEEL 2014), Napoli: Italy, 10-12 September 2014, 06677.

[28] V. Macillo, C. Castaldo, L. Fiorino, A. Formisano, B. Faggiano, and F. M. Mazzolani, "Evaluation of the Italian seismic code for the design of concentrically x-braced steel structures", In: Proceedings of $7^{\text {th }}$ European Conference on Steel and Composite Structures (EUROSTEEL 2014), Napoli: Italy, 10-12 September 2014

[29] A. Watanabe, Y. Hitomi, E. Saeki, A. Wada, and M. Fujimoto, "Properties of brace encased in buckling-restraining concrete and steel tube", In: Proceedings of $9^{\text {th }}$ World Conference on earthquake engineering, 1988, pp. 719-24.

[30] R. Tremblay, P. Bolduc, R. Neville, and R. DeVall, "Seismic testing and performance of buckling-restrained bracing systems", $\mathrm{Ca}$ nadian Journal of Civil Engineering, vol. 33, pp. 183-98, 2006.

[31] C.C. Chou, and S.Y. Chen, "Subassemblage tests and finite element analyses of sandwiched buckling-restrained braces", Engineering Structures, vol. 32, pp. 2108-21, 2010.

[32] M. Eryasar, and C. Topkaya, "An experimental study on steelencased buckling restrained brace hysteretic damper", Earthquake Engineering and Structural Dynamics, vol. 39, pp. 561-81, 2010.

[33] N. Hoveidae, and B. Rafezy, "Overall buckling behavior of allsteel buckling restrained braces", Journal of Constructional Steel Research, vol. 79, pp. 151-58, 2012.

[34] M. D’Aniello, G. Della Corte, and F.M. Mazzolani, "Seismic upgrading of rc buildings by buckling restrained braces: experimental results vs. numerical modeling", In: Proceedings of STESSA Conference 2006, Japan, 14-17 August 2006.
[35] M. D'Aniello, G. Della Corte, and F.M. Mazzolani, "Experimental tests of a real building seismically retrofitted by special bucklingrestrained braces", In: Proceedings of 2008 Seismic Engineering Conference Commemorating the 1908 Messina and Reggio Calabria Earthquake. Book Series: AIP Conference Proceedings, 2008, pp. 1513-20

[36] G. Della Corte, M. D'Aniello, R. Landolfo, and F.M. Mazzolani, "Review of steel buckling-restrained braces", Steel Construction, vol. 4, no. 2, pp. 85-93, 2011.

[37] G. Della Corte, M. D'Aniello, and R. Landolfo, "Field testing of all-steel buckling restrained braces applied to a damaged reinforced concrete building", Journal of Structural Engineering, ASCE DOI: 10.1061/(ASCE)ST.1943-541X.0001080, 2014

[38] T.J Maley, T.J. Sullivan, and G. Della Corte, "Development of a displacement-based design method for steel dual systems with buckling-restrained braces and moment-resisting frames", Journal of Earthquake Engineering, vol. 14, pp. 106-140, 2010.

[39] C. Wang, T. Usami, and J. Funayama, "Evaluating the influence of stoppers on the low-cycle fatigue properties of high-performance buckling-restrained braces", Engineering Structures, vol. 41, pp. 167-76, 2012.

[40] American Institute of Steel Construction, Inc. (AISC), "Seismic provisions for structural steel buildings", Standard ANSI/AISC 341-10. Chicago (IL, USA), 2010.

[41] ABAQUS user's manual, Dassault Systèmes Simulia Corp., Providence, RI, USA, 2010

[42] E.J. Kaufmann, B.R. Metrovich, and A.W. Pense, "Characterization of cyclic inelastic strain behavior on properties of A572 Gr. 50 and A913 Gr. 50 rolled sections", ATLSS Report No. 01-13, Lehigh Univ., Bethlehem, Pa, 2001.

[43] A. Korzekwa, and R. Tremblay, "Numerical simulation of the cyclic inelastic behavior of buckling restrained braces", In: Proceedings of STESSA conference 2009, Philadelphia: (USA), 16-20 August 2009

[44] A. Zsarnóczay, V. Budaházy, L.G. Vigh, and L. Dunai, "Cyclic hardening criteria in EN 15129 for steel dissipative braces", Journal of Constructional Steel Research, vol. 83, pp. 1-9, 2013.

[45] T. Takeuchi, J.F. Hajjar, R. Matsui, K. Nishimoto, and I.D. Aiken, "Effect of local buckling core plate restraint in buckling restrained braces”, Engineering Structures, vol. 44, pp. 304-11, 2012.

[46] J. Zhao, B. Wu, and J. Ou, "A novel type of angle steel bucklingrestrained brace: Cyclic behavior and failure mechanism", Earthquake Engineering and Structural Dynamics, vol. 40, pp. 1083-2, 2011.

[47] F. Genna, and P. Gelfi, "Analysis of the lateral thrust in bolted steel buckling-restrained braces. Part 1: experimental and numerical results", Journal of Structural Engineering, vol. 138, pp. 1231-43, 2012.

[48] F. Genna, and P. Gelfi, "Analysis of the lateral thrust in bolted steel buckling-restrained braces. Part 2: engineering analytical estimates", Journal of Structural Engineering, vol. 138, no. 10, pp. 1244-54, 2012.

Received: July 30, 2014
(C) D'Aniello et al.; Licensee Bentham Open.

This is an open access article licensed under the terms of the Creative Commons Attribution Non-Commercial License (http://creativecommons.org/licenses/by-nc/3.0/) which permits unrestricted, non-commercial use, distribution and reproduction in any medium, provided the work is properly cited. 